\title{
MODELLING OF FUTURE FLOOD RISK ACROSS CANADA DUE TO CLIMATE CHANGE
}

\author{
AYUSHI GAUR ${ }^{1}$, ABHISHEK GAUR $^{2} \&$ SLOBODAN P. SIMONOVIC $^{1}$ \\ ${ }^{1}$ Department of Civil and Environmental Engineering, The University of Western Ontario, Canada \\ ${ }^{2}$ National Research Council Canada, Canada
}

\begin{abstract}
Climate change has induced changes in key climate variables and hydrological cycles across Canada. With continuous emission of greenhouse gases, this trend is expected to continue over the $21 \mathrm{st}$ century and beyond. In this study, a macro-scaled hydrodynamic model is used to simulate $25 \mathrm{~km}$ resolution daily streamflow across Canada for historical (1961-2005) and future (2061-2100) timelines. Future projections from 21 General Climate Models (GCMs) following four Representative Concentration Pathways (RCPs) are used for analysis. Changes in the frequency and magnitude of historical 100-year and 250-year return period flood events and month of occurrence of peak flow are analyzed. Results obtained from uncertainty analysis for both return period flood events found that flood frequency will increase in most of northern Canada, southern Ontario, southern British Columbia, northern Alberta, Manitoba and Saskatchewan. However, northern British Columbia, northern Ontario, Manitoba and north-eastern Quebec will be facing a decrease in flood frequency. Aggregated results indicate early summertime extreme flows in the regions such as Alberta, Saskatchewan, Manitoba, Quebec, southern Ontario and some parts of Nunavut and Yukon territories, whereas the British Columbia region is mostly projected with increases in wintertime flooding. The projected flood hazard changes at 100 most populous Canadian cities and flow regulation infrastructure (FRI) are used to quantify future changes in flood risk. Results indicate that $40-60 \%$ of Canada's 100 most populated cities including many prominent cities such as Toronto and Montreal are high at risk of increased riverine flooding under climate change. Among the 1,072 FRIs analyzed, $45-60 \%$ of them can be expected to experience increases in flood magnitudes in the future whereas $25-60 \%$ of them can be expected to experience changes in flood timing.

Keywords: climate change, Canada, flooding frequency, catchment based macroscale floodplain model, uncertainty.
\end{abstract}

\section{INTRODUCTION}

Due to continuous greenhouse gas emissions, climate elements and their extremes have exhibited considerable shifts across the globe [1] including Canada [2]. Unprecedented changes in hydro-climatic regimes have been projected for different parts of Canada under climate change [3]. Floods are the most frequently occurring natural hazard in Canada [4]. With changes in climate and rapid urbanization, flooding events have been on the rise in Canada in recent decades. Many of the biggest flood disasters have occurred in populated Canadian cities such as: Montreal in 2012, Thunder Bay in 2012, Calgary in 2013 and 2010, Winnipeg in 1997 and 2009, and Toronto in 2005 and 2013.

General Climate Models (GCMs) simulate complex bio-geophysical and chemical processes occurring within the earth system and their interactions. For making future flows and flooding projections at catchment scale typically coarse resolution climate projections from GCMs are downscaled and used to generate streamflow response using a hydrologic model [3], [5].

Another approach commonly adopted by studies making future flow projections at continental or global spatial scales involve use of coarse scale gridded runoff projections made by GCMs and downscaling them to obtain higher resolution runoff estimates. Examples of studies adopting this approach include [6], where coarser resolution runoff simulations 
from GCMs were used to simulate high-resolution water level dynamics across the Amazon River basin using a Catchment-based Macro-scale Floodplain model (CaMaFlood) [7] used the same model to obtain $25 \mathrm{~km}$ resolution flow projections across the globe using coarser resolution runoff projections from $11 \mathrm{GCMs}$.

The objective of this paper is to investigate future changes in the frequencies and timings of 100-year and 250-year return period flooding events across Canada. To this end, a methodology similar to that used in [7] is adopted to generate high resolution flow estimates across Canada for historical and future timelines. A larger ensemble of future runoff than [7] that comprises of projections made by 21 GCMs under Representative Concentration Pathways (RCPs) RCP 2.6, RCP 4.5, RCP 6.0, and RCP 8.5 is considered for assessment. Flood risk at 100 most populous Canadian cities and 1,072 flow regulation infrastructure (FRI) as a consequence of projected changes in flood hazard are also quantified.

\section{DATA AND METHODS}

In this study, flow simulations are performed using the CaMaFlood model. In this model, river networks around the globe are discretized into hydrological units named unit catchments. The time evolution of water storage is calculated by solving water balance equation at each unit catchment which considers inflow from the upstream cells, outflow from the downstream cells, and flow generated at each unit catchment. River discharge and flow velocity are calculated using the local inertial equation along the river network map, which describes the upstream-downstream relationship of the unit-catchments. Flood inundation related parameters such as water level and flooded area are estimated using subgrid-scale topography of the floodplain. More details about the model can be found in the model description papers [8], [9].

Coarse resolution historical (1961-2005) and future (2061-2100) runoff simulations obtained from 21 GCMs included in the Coupled Model Inter-comparison Project Phase 5 (CMIP5) of the World Climate Research Programme (WCRP) [10] are used as input into globally calibrated CaMaFlood model and flow estimates covering the entire Canadian landmass are generated at $\sim 25 \mathrm{~km}$ spatial resolution for historical (1961-2005) and future (2061-2100) timelines. A spin-up period of two years is considered when generating historical/future timeline flows.

Generated historical and future flows are used to estimate future changes in the frequencies of historical 100- and 250-year floods across Canada. To do so, Generalized Extreme Value (GEV) distribution is fitted to historical annual maximum flow series. Flow quantiles corresponding to 100- and 250-year return period floods are estimated for historical timelines. GEV distribution is then fitted to annual maximums of future flow series, and return periods corresponding to historical 100- and 250-year flood magnitudes are estimated at all model grids located in Canada.

Future flood frequency projections from different GCMs (corresponding to a particular emission scenario) are aggregated and uncertainty magnitudes quantified for each $25 \mathrm{~km}$ grid. The robustness of flood frequency projections is taken into consideration when obtaining aggregated future flooding frequency information. The term 'robust' is used in this paper to refer to projections (projected changes) that are concurred by more than $50 \%$ of the GCM simulations. If equal numbers of projections convey increases/decreases in flooding frequencies in the future for a particular grid, then that grid is associated with 'non-robust' flood frequency projections. When aggregating future flood frequencies, projections that concur with the robust sign of change in flooding frequencies are considered for aggregation and uncertainty assessment. Aggregated flooding frequencies are calculated by finding median of future return period values, whereas uncertainty is quantified using eqn (1): 


$$
U_{r}=\frac{R P_{r, 0.75}-R P_{r, 0.25}}{R P_{r, 0.50}},
$$

where $U_{r}$ denotes the calculated uncertainty magnitude, and $P_{r, 0.75},{ }_{R P_{r, 0.50}}$, and ${ }_{R P_{r, 0.25}}$ denote 75 th, 50th, and 25th quantile of the robust flood frequency projections respectively.

When assessing changes in flood timing, flow events exceeding 95th flow quantile over the time-period of concern are considered as flooding events. Flood timing is defined in terms of the month when most numbers of flooding events are projected to occur over the timeperiod of interest. Monthly distributions of flooding events are analyzed at each $25 \mathrm{~km}$ grid and most frequent month of flooding is obtained for historical and future timelines. Flood timing values are aggregated at each $25 \mathrm{~km}$ grid by only taking into consideration projections from GCMs that are able to accurately simulate robust flood timing. Robust flow month is regarded as the month which is projected with most numbers of flooding events by more than $50 \%$ of the projections analyzed. If none of the months is concurred upon by more than $50 \%$ of the projections for a grid, then that grid is marked as having 'non-robust' flood timing results.

Changes in flood hazard at 100 most populated Canadian cities are calculated by extracting historical and future flooding frequencies at city center locations, and by using eqn (2) to quantify projected changes in flood hazard:

$$
\Delta F H_{c}=\frac{\left(R P_{c, h}-R P_{c, f}\right)}{\max \left(R P_{c, f}\right)-\min \left(R P_{c, f}\right)},
$$

where $\Delta F H_{c}$ denotes changes in flood hazard between historical and future timelines for a particular city (c), $R P_{c, h}$ denotes aggregated return-period of floods in historical timeline (i.e. 100 or 250 ), and $R P_{c, f}$ denotes the aggregated updated return-period of the floods in the future timeline.

Flood risk at the cities is calculated by combining the projected changes in flood hazard with current population of the cities $\left(P_{c}\right)$ using eqn (3):

$$
\Delta F R_{c}=\Delta F H_{c} \times \frac{\ln \left(P_{c}\right)-\min \left(\ln \left(P_{c}\right)\right)}{\max \left(\ln \left(P_{c}\right)\right)-\min \left(\ln \left(P_{c}\right)\right)} .
$$

As FRIs are sensitive to both timing and magnitudes of flood events, therefore flood hazard at the selected FRI locations is quantified by extracting aggregated historical and future flooding frequencies, and using eqn (2) to quantify changes in flood hazard. Furthermore, aggregated values of flood timings are obtained for historical and future timelines to access the hazard of future changes in flood timing.

\section{STUDY AREA}

Assessment of future changes in flooding frequencies and timings is performed across the entire Canadian landmass. The locations of 100 most populated cities and 1,072 flow regulating infrastructures that are considered for assessment in this study are also shown in Fig. 1 as red dots and blue crosses respectively.

\section{RESULTS AND DISCUSSION}

Aggregated future flooding frequencies of historical 100-year and 250-year flooding events are presented in Figs 2 and 3 respectively. The regions presented in blue (brown) are projected with future increases (decreases) in flooding frequencies, whereas regions 


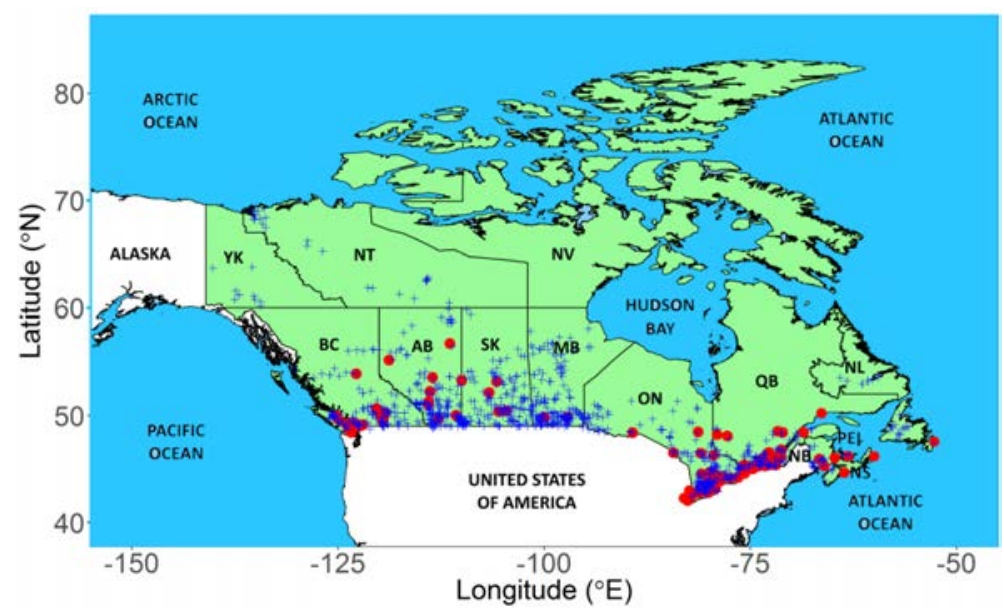

Figure 1: The study region with the location of cities and flow regulation locations considered for assessment in this study.
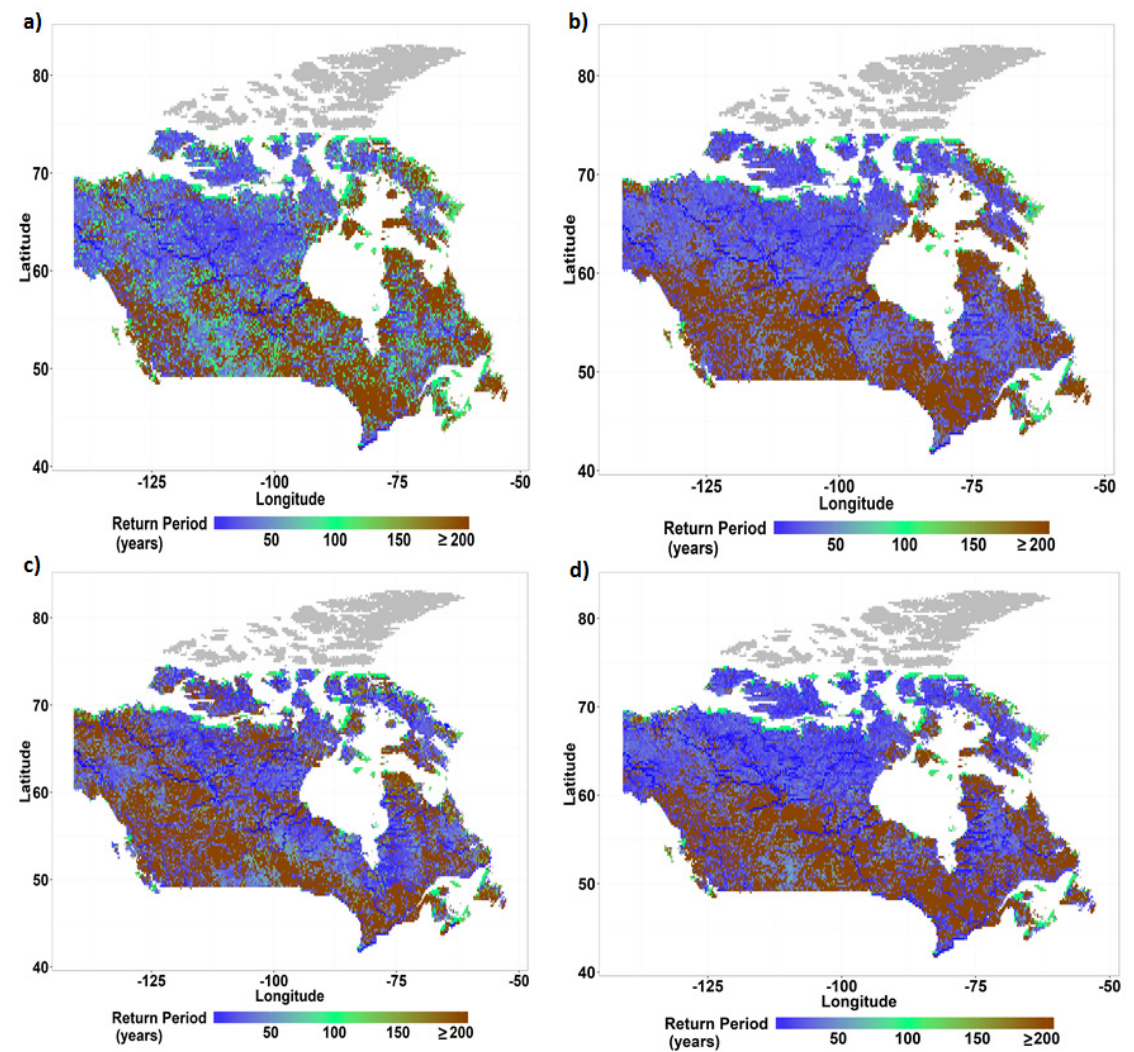

Figure 2: Future return periods of historical 100-year flood event for: a) RCP 2.6; b) RCP 4.5; c) RCP 6.0; and d) RCP 8.5. 
a)

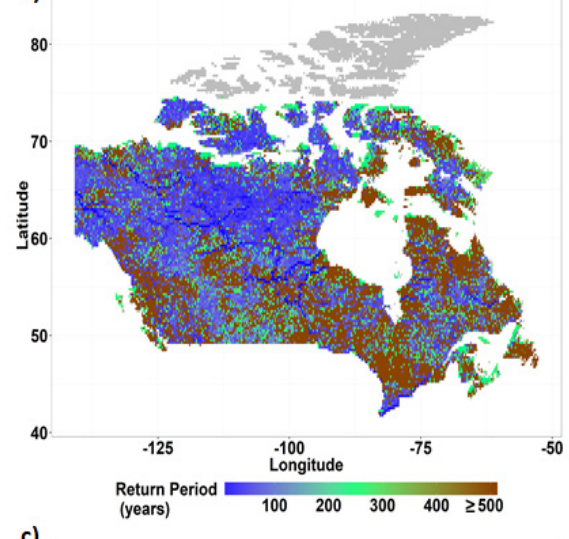

$$
\text { c) }
$$

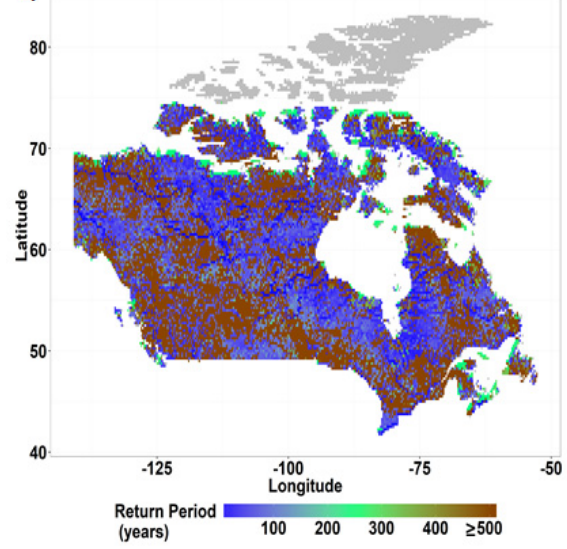

b)

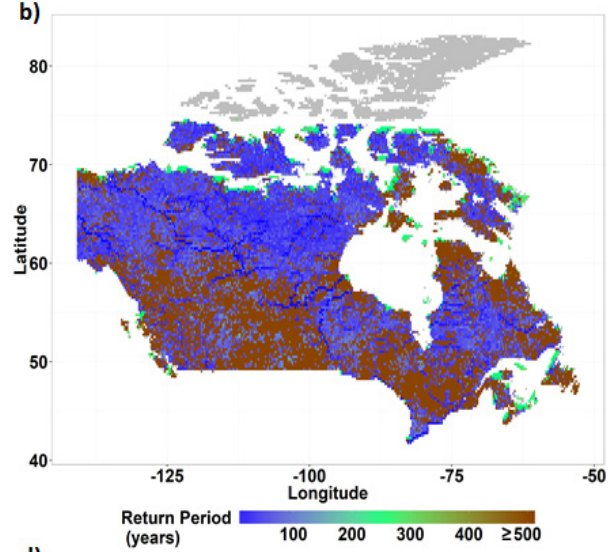

.

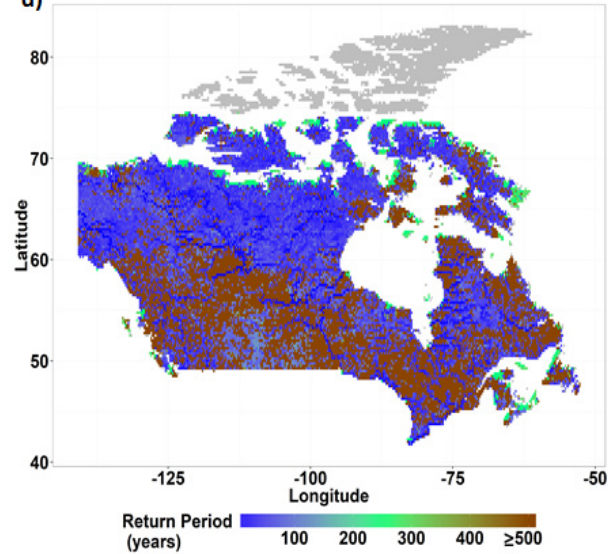

Figure 3: Future return periods of historical 250-year flood event for: a) RCP 2.6; b) RCP 4.5 ; c) RCP 6.0 ; and d) RCP 8.5.

presented in green are projected with no considerable changes in flooding frequencies. Regions where non-robust projections of flood frequencies are obtained are shown in white.

Results indicate that flooding frequencies of historical 100-year and 250-year return period flood can be expected to increase considerably in the northern regions of Canada with return period of historical 100-year floods projected to reduce to 50-year or less in the future. On the other hand, a decrease in flooding frequencies can be expected for regions including British Columbia, Alberta, Manitoba, and northern Saskatchewan with return period of historical 100-year floods projected to increase to 165-200 years in the future. Parts of Nova Scotia, Newfoundland and Labrador, and northernmost regions of Nunavut, and south-west British Columbia can be expected to experience no considerable changes in future flooding frequencies. Between the four RCPs, similar spatial distributions of future flood frequency changes are projected for RCP 4.5 and RCP 8.5. Under RCP 6.0 provinces of Yukon Territory, Northwest Territory, and Nunavut are projected with higher flood frequencies than that projected in RCP 4.5 and RCP 8.5. Projections made under RCP 2.6 are associated with larger uncertainty than that projected for other RCPs. The spatial distributions of projected changes are found similar for both 100-year and 250-year return period flooding events. 
Spatial distributions of flood timing obtained for historical and future timelines are presented in Fig. 4 for the extreme RCP: RCP 8.5. In the figure, months where wintertime precipitation is likely to contribute to peaks i.e. November, December, January, February are shown in the shades of pink, months where snow-melt can be a dominant factor i.e. March, April, May are shown in the shades of blue, while months where summertime convection can be a dominant contributor to peaks i.e. June, July, August, September, October are shown in the shades of green. Grids with non-robust flood timing results are shown in grey color. Results clearly highlight projected future increases in the total area effected by snowmelt driven floods (shown in the shades of blue), as well as an earlier onset of snowmelt driven floods in the future. These changes are most evident in the northern and central regions of Canada.

The spatial distribution of future peak flow months is found similar in case of the four RCPs except that GCMs are found to be more uncertain about peak flow month in cases of RCP 4.5 and RCP 8.5 than in cases of RCP 2.6 and RCP 6.0.

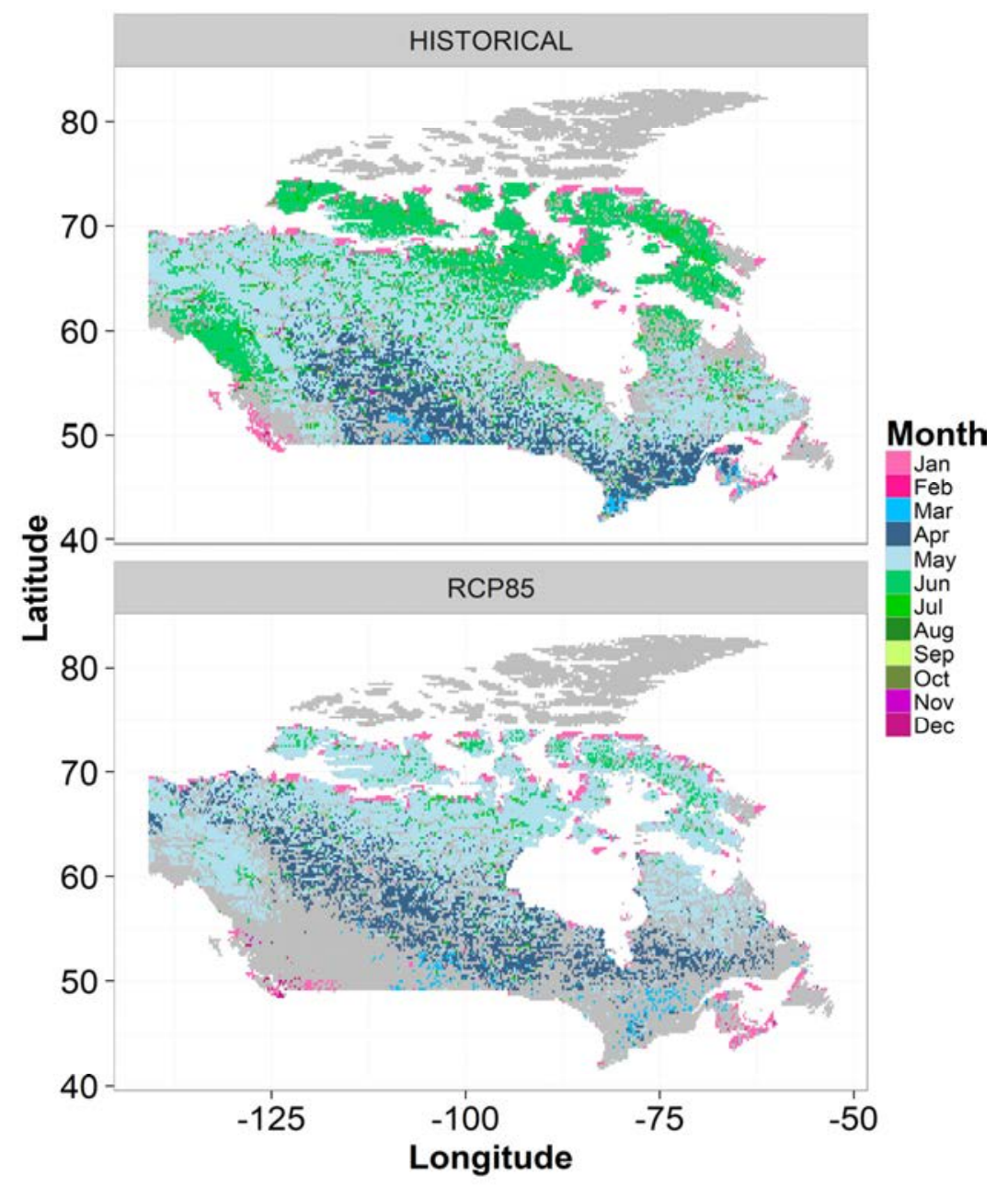

Figure 4: Flood timing obtained for historical and future timelines for RCP 8.5. 
The flood-hazard change results are summarized in Fig. 5 for historical 100-year return period floods for 100 most populous Canadian cities. It is obtained that the cities located in southern Ontario, southern British Columbia, southern Alberta, southern Saskatchewan, parts of Nova Scotia and Quebec are projected with future increases in flood-hazard and floodrisk. From the assessment of changes in flood-hazard and flood-risk, it is obtained that 40 $60 \%$ of the cities can be expected to experience future increases in flood hazard under different RCPs. Largest numbers of cities with decreasing flooding frequencies are obtained for RCP 8.5, followed by RCP 6.0, and then RCP 2.6 and RCP 4.5.

A subset of these results for ten most populous cities is presented in Tables 1 and 2 respectively. It can be noted that some highly populated cities are projected with significantly lower return periods of historical 100-year floods such as Toronto (15-32 years), Montreal (11-26 years), Quebec (26-27 years), Hamilton (27-54 years), and Kitchener (26-75 years) according to two or more RCPs. The same is also reflected in the risk values for these cities presented in Table 2. It can also be noted that the projections of return period change made for different cities differ considerably between different RCPs. For example, Vancouver is projected with large increases in return periods of historical 100-year return period floods
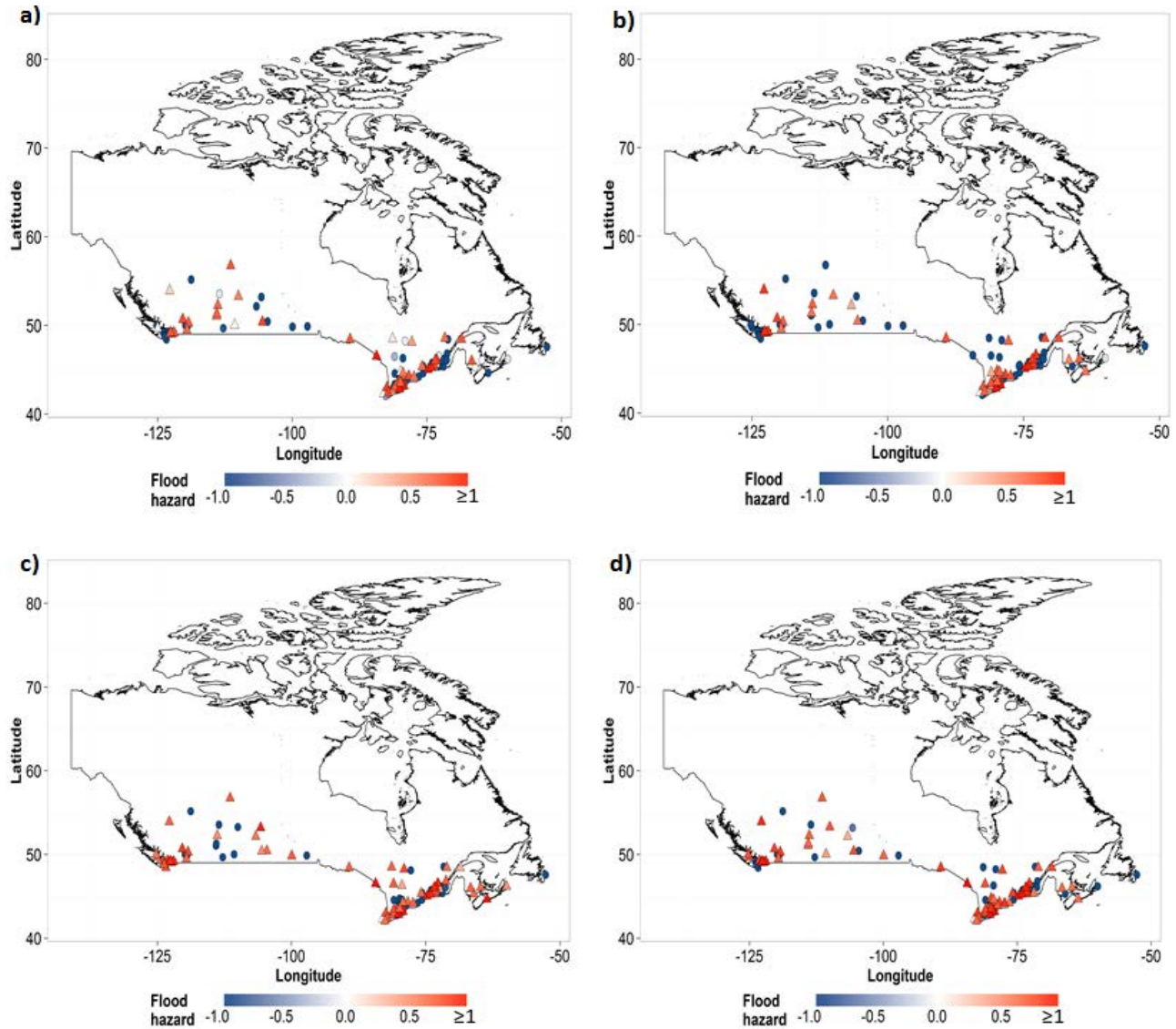

Figure 5: Flood hazard for 100 most populated cities in Canada under: a) RCP 2.6; b) RCP 4.5; c) RCP 6.0; and d) RCP 8.5. Positive values are presented as triangles whereas negative values are presented as dots. 
Table 1: Projected future return periods of historical 100-year and 250-year return period flood events for 10 most populated Canadian cities. Return periods greater than 1,000 are only provided categorically. Cases projected with future increases (decreases) in flood-hazard are highlighted in blue (red).

\begin{tabular}{|l|c|c|c|c|c|c|c|c|}
\hline \multirow{2}{*}{ City } & \multicolumn{2}{|c|}{ RCP 2.6 } & \multicolumn{2}{c|}{ RCP 4.5 } & \multicolumn{2}{c|}{ RCP 6.0 } & \multicolumn{2}{c|}{ RCP 8.5 } \\
\cline { 2 - 9 } & $\begin{array}{l}100- \\
\text { year }\end{array}$ & $\begin{array}{l}250- \\
\text { year }\end{array}$ & $\begin{array}{l}100- \\
\text { year }\end{array}$ & $\begin{array}{l}250- \\
\text { year }\end{array}$ & $\begin{array}{c}100- \\
\text { year }\end{array}$ & $\begin{array}{c}250- \\
\text { year }\end{array}$ & $\begin{array}{c}100- \\
\text { year }\end{array}$ & $\begin{array}{c}250- \\
\text { year }\end{array}$ \\
\hline Toronto & 22 & 37 & 32 & 46 & 32 & 39 & 15 & 23 \\
\hline Montreal & 26 & 38 & 22 & 32 & 18 & 25 & 11 & 16 \\
\hline Vancouver & $\geq 1000$ & $\geq 1000$ & $\geq 1000$ & $\geq 1000$ & 20 & 28 & 37 & 32 \\
\hline Calgary & 46 & 94 & $\geq 1000$ & $\geq 1000$ & $\geq 1000$ & $\geq 1000$ & 49 & 85 \\
\hline Ottawa & 278 & $\geq 1000$ & $\geq 1000$ & $\geq 1000$ & 507 & $>1000$ & $\geq 1000$ & $\geq 1000$ \\
\hline Edmonton & 104 & 284 & 289 & $>1000$ & 383 & $>1000$ & 533 & $>1000$ \\
\hline Hamilton & 37 & 56 & 51 & 78 & 54 & 67 & 27 & 56 \\
\hline Quebec & 910 & $\geq 1000$ & $\geq 1000$ & $\geq 1000$ & 27 & 49 & 26 & 75 \\
\hline Winnipeg & 245 & 740 & 569 & $>1000$ & $\geq 1000$ & $\geq 1000$ & 406 & $\geq 1000$ \\
\hline Kitchener & 26 & 47 & 75 & 86 & 45 & 57 & 29 & 60 \\
\hline
\end{tabular}

Table 2: Projected changes in risk for historical 100-year and 250-year return flood events for 10 most populated cities. Risk change values less than -10 are only shown categorically. Cases projected with future increases (decreases) in flood-risk are highlighted in blue (red).

\begin{tabular}{|l|c|c|c|c|c|c|c|c|}
\hline \multirow{3}{*}{ City } & \multicolumn{2}{|c|}{ RCP 2.6 } & \multicolumn{2}{c|}{ RCP 4.5 } & \multicolumn{2}{c|}{ RCP 6.0 } & \multicolumn{2}{c|}{ RCP 8.5 } \\
\cline { 2 - 9 } & $\begin{array}{l}100- \\
\text { year }\end{array}$ & $\begin{array}{c}250- \\
\text { year }\end{array}$ & $\begin{array}{c}100- \\
\text { year }\end{array}$ & $\begin{array}{c}250- \\
\text { year }\end{array}$ & $\begin{array}{c}100- \\
\text { year }\end{array}$ & $\begin{array}{c}250- \\
\text { year }\end{array}$ & $\begin{array}{c}100- \\
\text { year }\end{array}$ & $\begin{array}{c}250- \\
\text { year }\end{array}$ \\
\hline Toronto & 0.8 & 0.9 & 0.7 & 0.8 & 0.7 & 0.8 & 0.9 & 0.9 \\
\hline Montreal & 0.7 & 0.8 & 0.7 & 0.8 & 0.8 & 0.8 & 0.8 & 0.9 \\
\hline Vancouver & $\leq-10$ & $\leq-10$ & $\leq-10$ & $\leq-10$ & 0.7 & 0.7 & 0.7 & 0.7 \\
\hline Calgary & 0.4 & 0.4 & $\leq-10$ & $\leq-10$ & $\leq-10$ & $\leq-10$ & 0.4 & 0.5 \\
\hline Ottawa & -1.2 & $\leq-10$ & $\leq-10$ & $\leq-10$ & -2.8 & -3.5 & $\leq-10$ & $\leq-10$ \\
\hline Edmonton & 0 & -0.1 & -1.3 & -5.4 & -1.9 & -4.3 & -2.9 & -4.8 \\
\hline Hamilton & 0.4 & 0.4 & 0.4 & 0.5 & 0.5 & 0.5 & 0.4 & 0.4 \\
\hline Quebec & -5.1 & -5.8 & $\leq-10$ & $\leq-10$ & 0.5 & 0.5 & 0.5 & 0.5 \\
\hline Winnipeg & -0.9 & -1.2 & -3.0 & -4.9 & $\leq-10$ & $\leq-10$ & -1.9 & $\leq-6.4$ \\
\hline Kitchener & 0.4 & 0.4 & 0.5 & 0.5 & 0.4 & 0.4 & 0.4 & 0.4 \\
\hline
\end{tabular}

under RCP 2.6, and RCP 4.5, but is projected with decreases in return periods under RCP 6.0, and RCP 8.5. This observed difference in the results for different RCPs is found to be due to differences in runoff projections made by the GCMs under different emission scenarios. Although the direction of change projected for future flood-hazard and flood-risk is found to be the same for all cities, their relative magnitudes are found to differ for floodhazard and flood-risk.

Future flooding frequencies obtained at the analyzed FRIs for historical 100-year flood magnitudes is presented in Fig. 6. An assessment of projected changes in flooding frequencies suggest that the sign of change in future flooding frequencies is uncertain in close 

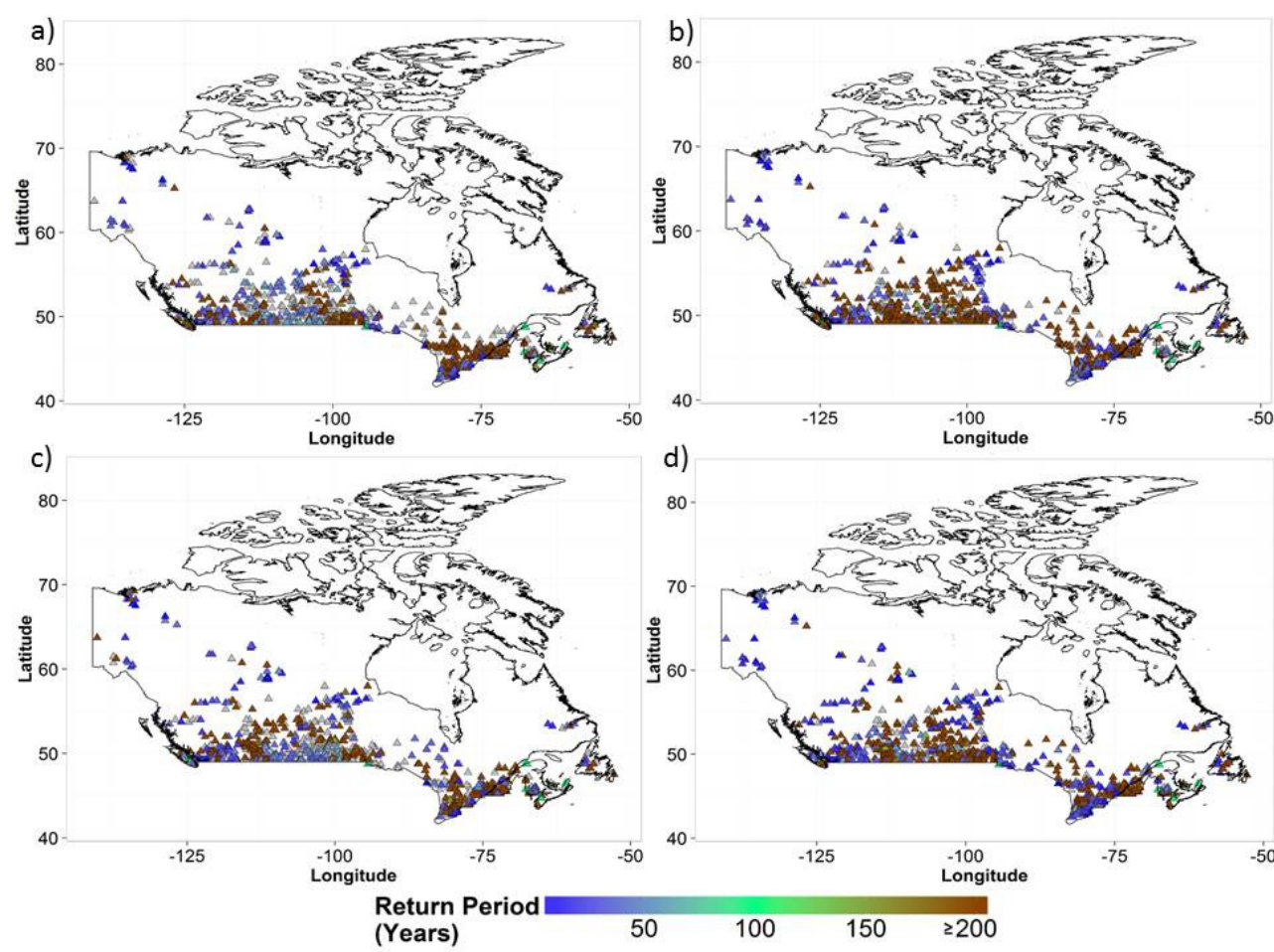

d)

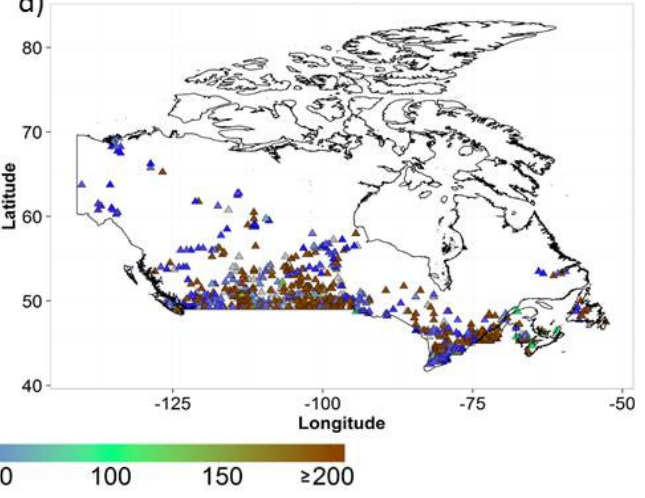

Figure 6: Updated flood frequency of historical 100-year flood magnitudes at FRIs in Canada for: a) RCP 2.6; b) RCP 4.5; c) RCP 6.0; and d) RCP 8.5. FRIs with uncertain results are shown in grey.

to $20-40 \%$ of all 1,072 FRIs analyzed. Among the FRIs projected with a robust sign of change, $40-60 \%$ of the FRIs prominently distributed in south-western Ontario, west coast, and northern Canada are projected with future increases in flood hazard due to flooding frequencies. Among the four RCPs, largest numbers of FRIs projected with future increases in flood-hazard are found to be associated with RCP 8.5.

Finally, from the assessment of flood timing projected at FRI locations for historical and future timelines, it is noted that a large fraction of flooding events occur in the months when snowmelt is one of the key processes that drives flow generation. It is also noted that the extreme flow month at many FRIs located in southern Ontario and Quebec are projected to shift from April to March between historical and future timelines. Extreme flow months at many FRIs located in central Ontario and northern Canada are projected to transition from May to April. These results suggest early snowmelt and related flow extremes to be experienced at many regulated flow gauging stations in Canada. FRIs located in southern British Columbia, Nova Scotia and New Brunswick are projected with extreme flows during the winter months in both historical and future timelines. This wintertime peak flows are likely to be contributed by wintertime precipitation and large scale climate patterns, and is likely to remain unchanged in the future.

Finally, large uncertainty in flood-timing results is obtained with $50-80 \%$ of the FRIs projected with uncertain flood-timing results in at least one of the two timelines analyzed. Most uncertainty for future extreme flow months is found to be associated with RCP 8.5 and 
in the Alberta, Manitoba and Saskatchewan provinces of Canada. Among the stations where robust predictions of extreme flow months are obtained, $25-60 \%$ of the FRIs are obtained with future projected changes in flood timing.

\section{CONCLUSIONS}

Changes in the frequencies and timings of flooding events across Canada as a consequence of climate change are investigated in this study. An ensemble of 84 future runoff projections made by $21 \mathrm{GCMs}$ is analyzed. A state-of-the-art mesoscale hydrodynamic model: CaMaFlood is used to simulate $\sim 25 \mathrm{~km}$ spatial resolution historical and future projected flows from coarser resolution GCM runoff estimates. The projections made by different GCMs are aggregated using an approach that takes into consideration robustness of the projections (projected changes). Spatial distributions of projected flood frequency changes convey that the northern provinces of Canada: Northwest Territories, Yukon Territory, and Nunavut, southwestern Ontario, north-eastern Quebec, and southern prairies can be expected to have higher flood frequencies in the future with return period of 100-year historical flood to become 10-60 years by the end of the 21 st century. On the contrary, northern prairies and north-central Ontario can be expected to experience lower flood frequencies with return period of 100-year historical flood to become 160-200 years in the future. This projected increase (decrease) in flooding frequencies in above mentioned areas is also found to be among the least (most) uncertain changes projected for Canada indicating that flood exposure can be expected to increase across Canada in the future.

An assessment of projected changes in future flood timing indicates earlier snowmelt in almost all regions of Canada. This is expected, given that future temperatures are projected to increase across Canada under the influence of climate change [2]. Signs of increases in snowmelt driven floods, and earlier snowmelt have been detected in historical flow records as well as have been projected for many Canadian rivers [11]. The results obtained are thus also in line with the findings made in many previous studies performed at catchment scales in Canada.

Assessment of projected changes at 100 most populous Canadian cities suggest that $40-60 \%$ of the cities can be expected to experience higher flood-hazard and flood-risks in the future including some of the largest and most populous Canadian cities such as Toronto and Montreal. Some large cities such as Vancouver and Ottawa have also been projected with large uncertainties originating from differences in runoff projections made for different RCPs.

Finally, a large number of these FRIs (20-40\% in case of flooding frequencies and $55-80 \%$ in case of flood-timing) are projected with uncertain flood characteristics. Where robust estimates are obtained, $40-60 \%$ of the FRIs are predicted with future increases in flooding frequencies and $30-60 \%$ of the FRIs are predicted with future changes in flood timing. Even in the face of future runoff modelling uncertainties associated with the GCMs, these results highlight that Canadian population is under the risk of being exposed to increasing flood hazard and risk in future under climate change. The results obtained in this study can serve as useful guides for decision-makers in Canada for identifying flood-hazard areas under changing climate, and prioritise appropriate mitigation and response efforts in these areas.

\section{ACKNOWLEDGEMENTS}

The authors extend appreciation to Dr Dai Yamazaki for providing globally calibrated CaMaFlood model, as well acknowledge the financial support from Chaucer Syndicates (London, UK) and Natural Sciences and Engineering Research Council of Canada (NSERC). 


\section{REFERENCES}

[1] IPCC, Summary for Policymakers. Climate Change 2013: The Physical Science Basis. Contribution of Working Group I to the Fifth Assessment Report of the Intergovernmental Panel on Climate Change, eds T.F. Stocker et al., Cambridge University Press: Cambridge and New York, 2013.

[2] ECCC (Environment and Climate Change Canada), Climate Data and Scenarios for Canada: Synthesis of Recent Observation and Modelling Results, 2016.

[3] Mandal, S. \& Simonovic, S.P., Quantification of uncertainty in the assessment of future streamflow under changing climate conditions. Hydrological Processes, 31, pp. 2076-2094, 2017.

[4] Sandink, D., Urban Flooding in Canada, Institute for Catastrophic Loss Reduction: Toronto, 2013.

[5] Linde, A.H., Aerts, J.C.J.H., Bakker, A.M.R. \& Kwadijk, J.C.J., Simulating low probability peak discharges for the Rhine basin using resampled climate modeling data. Water Resources Research, 46, W04512, 2010.

[6] Yamazaki, D. et al., Analysis of the water level dynamics simulated by a global river model: A case study in the Amazon River. Water Resources Research, 48, W09508, 2012.

[7] Hirabayashi, Y. et al., Global flood risk under climate change. Nature Climate Change, 3, pp. 816-821, 2013.

[8] Yamazaki, D., Kanae, S., Kim, H. \& Oki, T., A physically-based description of floodplain inundation dynamics in a global river routing model. Water Resources Research, 47, W04501, 2010.

[9] Yamazaki, D., de Almeida, G.A.M. \& Bates, P., Improving computational efficiency in global river models by implementing the local inertial flow equation and a vectorbased river network map. Water Resources Research, 49(11), pp. 7221-7235, 2013.

[10] Taylor, K.E., Stouffer, R.J. \& Meehl, G.A., An overview of CMIP5 and the experiment design. American Meteorological Society, 93, pp. 485-498, 2012.

[11] Poitras, V., Sushama, L., Segleniek, F., Khaliq, M.N. \& Soulis, E., Projected changes to streamflow characteristics over western Canada as simulated by the Canadian RCM. J. Hydrometeorol., 126, pp. 1395-1413, 2011. 